complicate hypertension. Our findings suggest that age at repair might not be as important in the development of left ventricular hypertrophy and vascular damage in postcoarctectomy patients as is often believed.

Our findings support the hypothesis that aortic coarctation forms part of an extensive developmental abnormality of the proximal systemic arterial system also involving the left ventricle and the carotid arteries. Nowadays, early correction is recommended to reduce the risk of future sustained hypertension, but its effect on the left ventricle and proximal arteries might be less important than previously thought.

\section{References}

1. Johnson MC, Gutierrez FR, Sekarski DR, Ong CM, Canter CE. Comparison of ventricular mass and function in early versus late repair of coarctation of the aorta. Am J Cardiol. 1994;73:698-701.

2. Vriend JW, van Montfrans GA, Romkes HH, Vliegen HW, Veen G, Tijssen JG, et al. Relation between exercise-induced hypertension and sustained hypertension in adult patients after successful repair of aortic coarctation. J Hypertens. 2004;22:501-9.

3. Bottini PB, Carr AA, Prisant LM, Flickinger FW, Allison JD, Gottdiener JS. Magnetic resonance imaging compared to echocardiography to assess left ventricular mass in the hypertensive patient. Am J Hypertens. 1995;8:221-8.

\title{
Partial left ventriculectomy for infantile ischemic cardiomyopathy caused by anomalous origin of the left coronary artery from the pulmonary artery
}

\begin{abstract}
Masaaki Yamagishi, MD, PhD, ${ }^{a}$ Keisuke Shuntoh, MD, ${ }^{a}$ Takeshi Shinkawa, MD, Takahiro Hisaoka, MD, ${ }^{a}$ Mitsugu Ogawa, MD, ${ }^{a}$ Keitarou Kohshi, MD, ${ }^{a}$ Hitoshi Yaku, MD, PhD, You Kajiyama, MD, ${ }^{\mathrm{b}}$ and Kenji Hamaoka, MD, PhD, Kyoto, Japan
\end{abstract}

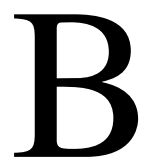
road ischemia of the left ventricle and subsequent severe ventricular failure are unavoidable in infants with anomalous origin of the left coronary artery from the pulmonary artery (ALCAPA). Here we report the first case of successful partial left ventriculectomy in a 3-month-old infant with severe ischemic cardiomyopathy caused by ALCAPA and vanishingly scarce collateral vessels.

\section{Clinical Summary}

A 3-month-old female infant weighing $5300 \mathrm{~g}$ with congestive heart failure was referred to our hospital. Abnormal Q waves were detected in leads I and aVL and precordial leads V4 through V6 on electrocardiography. Echocardiography demonstrated marked left ventricular (LV) dilatation with significant reduction in ventricular wall thickness (Figure 1, left). The LV end-diastolic diameter was $48 \mathrm{~mm}$. Wall motion showed marked diffuse deterioration. Shortening fraction was reduced to $7 \%$. Posterolateral wall thickness

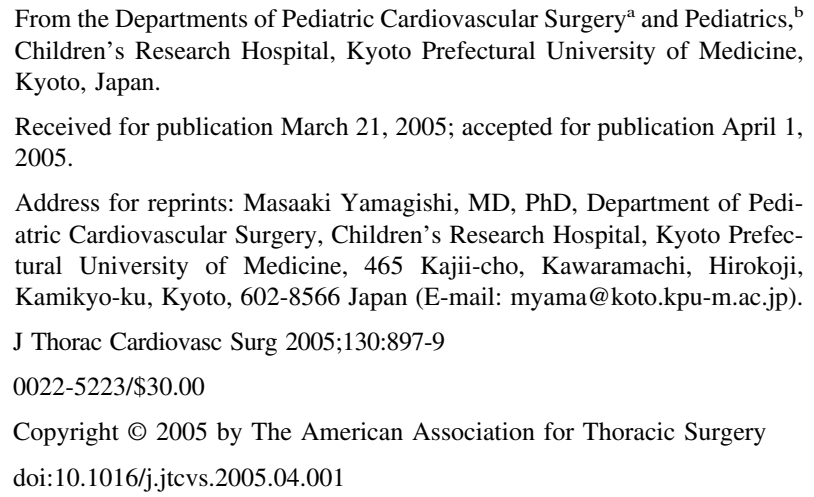
atric Cardiovascular Surgery, Children's Research Hospital, Kyoto Prefectural University of Medicine, 465 Kajii-cho, Kawaramachi, Hirokoji, Kamikyo-ku, Kyoto, 602-8566 Japan (E-mail: myama@koto.kpu-m.ac.jp)

J Thorac Cardiovasc Surg 2005;130:897-9

$0022-5223 / \$ 30.00$

Copyright $\odot 2005$ by The American Association for Thoracic Surgery doi:10.1016/j.jtcvs.2005.04.001

faded to $2 \mathrm{~mm}$. The papillary muscles and endocardium showed markedly increased echogenicity. Severe mitral regurgitation was also ob-

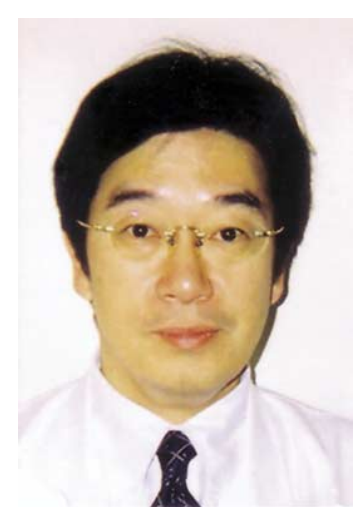

Dr Yamagishi served. The left coronary artery originated from the left posterior sinus of the pulmonary artery. ${ }^{201}$ Thallium myocardial scintigraphy demonstrated broad ischemia and the absence of myocardial viability at the posterolateral wall of the left ventricle.

The infant underwent reimplantation of the left coronary artery and partial left ventriculectomy. After institution of moderately hypothermic cardiopulmonary bypass and subsequent chemical cardiac arrest, the pulmonary artery was transected at the bifurcation. The pulmonary cuff, including the left coronary orifice, was harvested and implanted directly into the left lateral aortic wall. This was followed by mitral annuloplasty at the posterocommissural line.

The LV wall showed dark red discoloration and was markedly reduced in thickness. Island-shaped scar formations were also observed. The lateral LV wall measuring $25 \times 40 \mathrm{~mm}$ was resected in an elliptical shape along the left ascending coronary artery (Figure 2). Histologic examination showed significant transmural myocardial infarction. The ventriculotomy was closed longitudinally with reinforcing polytetrafluoroethylene felt strips. Coercive weaning from the cardiopulmonary bypass was not attempted because the patient had a high left atrial pressure of $23 \mathrm{~mm} \mathrm{Hg}$. The infant was placed on an extracorporeal circulatory support system and was weaned easily from this circulatory support system on the third postoperative day.

Postoperative echocardiography (Figure 1, right) showed marked improvement in LV function and a significant decrease in 


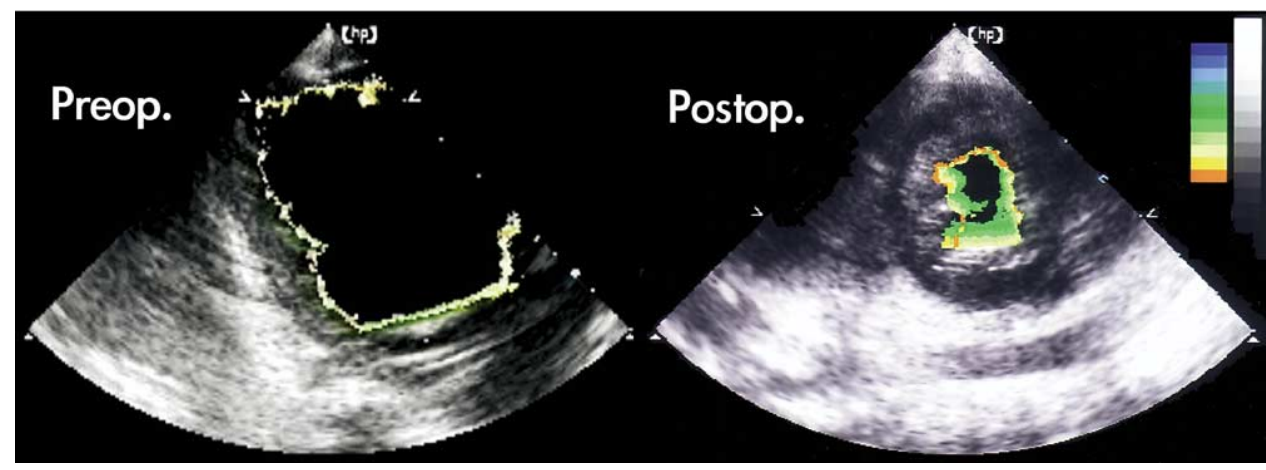

Figure 1. Left, Preoperative echocardiography; right, postoperative echocardiography.

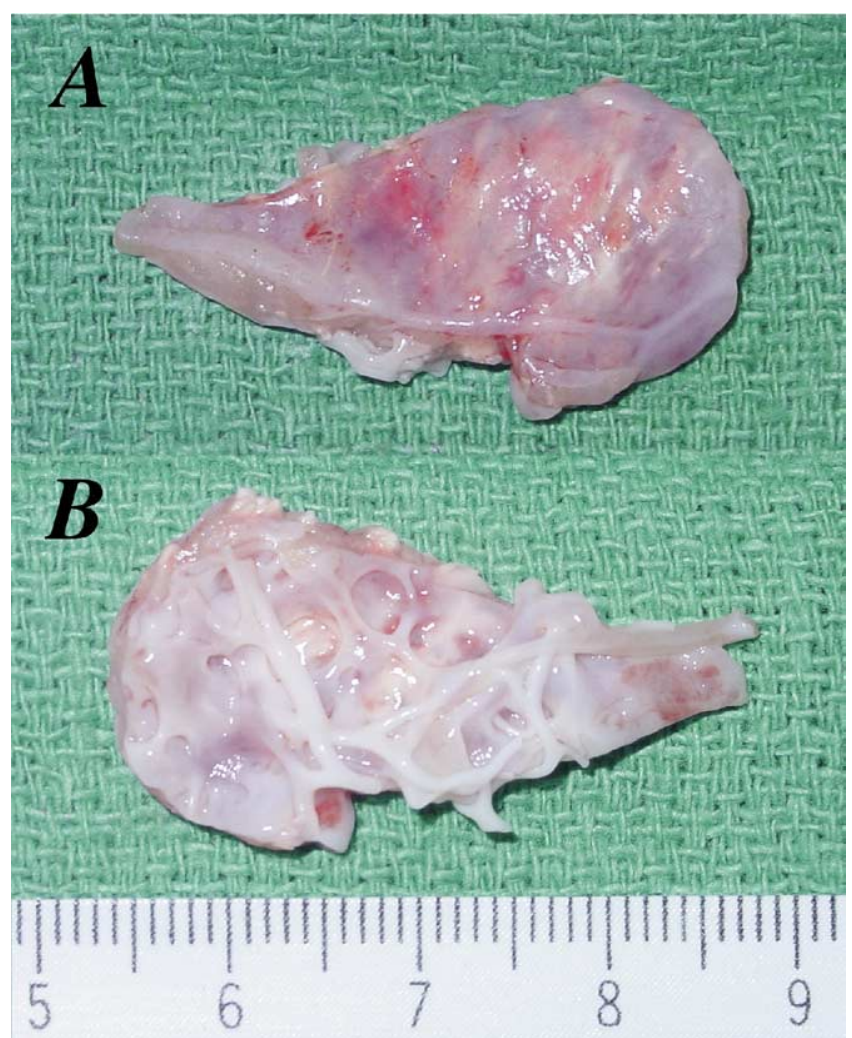

Figure 2. Macroscopic findings of the resected $\mathrm{LV}$ wall showing transmural, large, island-shaped scar formations and significant subendocardial fibrosis. The wall thickness was reduced to 2 mm. A, Epicardial aspect; B, endocardial aspect.

cavity volume. The LV shortening fraction was improved to $26 \%$. The LV end-diastolic diameter was decreased to $29 \mathrm{~mm}$, LV wall thickness returned to $6.5 \mathrm{~mm}$, and no mitral regurgitation was detected. Postoperative ${ }^{201}$ thallium myocardial scintigraphy showed considerable improvement of myocardial viability in all segments of the LV wall.

\section{Discussion}

In infants with ALCAPA, the myocardium of the left ventricle is exposed to severe ischemia because of initial depletion of the coronary flow and subsequent coronary-pulmonary steal. However, LV function frequently recovers after surgical repair in most infants ${ }^{1}$ because potential recoverable myocardial contractility is preserved by immediate development of the collateral blood supply to varying degrees. On the other hand, if broad transmural infarction, ensuing fibrosis or fibroelastosis, and ischemic cardiomyopathy go to completion because of underdevelopment of the collateral vessels, sufficient restoration of LV function is not expected despite 2-coronary revascularization. In addition, refractory low cardiac output early after the operation cannot be overcome in most cases. In such cases, prompt reduction of LV wall stress and immediate improvement of LV muscle mass-cavity volume mismatch are indispensable for amelioration of mortality and morbidity.

Partial left ventriculectomy is an established procedure for treatment of nonischemic dilated cardiomyopathy in adult patients to decrease wall stress and improve contractility. ${ }^{2,3}$ Encouraging results of partial left ventriculectomy combined with mitral valve repair for infantile dilated cardiomyopathy have also been reported. ${ }^{4,5}$ These observations suggested that partial left ventriculectomy is applicable even in infantile ischemic cardiomyopathy. In infants with ischemic cardiomyopathy caused by ALCAPA, partial resection of the LV wall, in which viability of the myocardium was severely reduced by severe ischemia, decreases wall stress and increases the potential of recoverable myocardial contractility of the residual LV wall. Nevertheless, it must be noted that indications of partial left ventriculectomy for ALCAPA should be confined to transmural infarction and irreversible fibrosis at the posterolateral wall, along with marked LV dilatation and reduced ventricular wall thickness, because LV function in infantile ALCAPA still has the potential for recovery after 2-coronary revascularization. $^{1}$

In conclusion, we present the first report of successful partial left ventriculectomy in an infant with severe ischemic cardiomyopathy caused by ALCAPA. Partial left ventriculectomy has a beneficial effect on restoration of ventricular function for infantile ALCAPA with incurable ischemic cardiomyopathy. 


\section{References}

1. Michielon G, Di Carlo D, Brancaccio G, Guccione P, Mazzera E, Toscano A, et al. Anomalous coronary artery origin from the pulmonary artery: correlation between surgical timing and left ventricular function recovery. Ann Thorac Surg. 2003;76:581-8.

2. Batista RJV, Santos JLV, Takeshita N, Bocchino L, Lima PN, Cunha MA. Partial left ventriculectomy to improve left ventricular function in end-stage heart disease. J Card Surg. 1996;11:96-8.
3. Suma H, Isomura T, Horii T, Sato T, Kikuchi N, Iwahashi K, Hosokawa J. Nontransplant cardiac surgery for end-stage cardiomyopathy. J Thorac Cardiovasc Surg. 2000;119:1233-45.

4. Yoshii S, Hosaka S, Takahashi W, Amano H, Abraham SJK, Kaga S, et al. Partial left ventriculectomy in an infant with dilated cardiomyopathy. J Thorac Cardiovasc Surg. 1999;117:616-8.

5. Berger S, Tweddell JS, Frommelt PC, Weinhaus L. Partial left ventriculectomy for dilated cardiomyopathy in a newborn. J Thorac Cardiovasc Surg. 1999;117:1017-8.

\title{
Lung mass after pulmonary artery catheterization: Beware of the pulmonary artery false aneurysm
}

\author{
Cliff K. Choong, FRACS, and Bryan F. Meyers, MD, St Louis, Mo
}

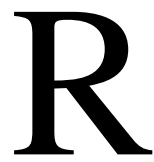

upture of the pulmonary artery (PA) or one of its branches during a right heart catheterization is a complication that is rare but remains fatal in almost $50 \%$ of cases. ${ }^{1}$ We report a case of PA false aneurysm caused by PA rupture, which presented as a lung mass 10 days after catheterization, that was correctly identified and successfully treated.

\section{Clinical Summary}

An 81-year-old woman with a history of atrial fibrillation presented with fatigue and decreased exercise tolerance and clinically was in congestive heart failure. Echocardiography revealed severe aortic stenosis and mild mitral regurgitation. She underwent cardiac catheterization for further evaluation, including PA catheterization. She had some hemoptysis immediately after the procedure, which resolved without further episode. Postprocedure chest radiography revealed no abnormality apart from changes consistent with congestive heart failure. Ten days later, a repeat chest radiograph revealed a rounded right lung mass (Figure 1, A). Chest computed tomography was performed to further investigate the lung mass, and this showed the mass to be in the right hilum of the lower lobe in contiguity with the right PA (Figure 1, B-D). A false aneurysm of the PA was suspected, and she underwent a right PA angiography, which confirmed it (Figure 2, $A$ and $B$ ). The aneurysm was successfully treated nonsurgically with coil embolization to occlude the inflow neck of the aneurysm (Figure 2, $C$ and $D$ ).

From the Division of Cardiothoracic Surgery, Department of Surgery, Washington University School of Medicine, St Louis, Mo.

Received for publication Jan 5, 2005; accepted for publication Jan 13, 2005

Address for reprints: Bryan F. Meyers, MD, Division of Cardiothoracic Surgery, Department of Surgery, Washington University School of Medicine, St Louis, MO 63119 (E-mail: meyersb@msnotes.wustl.edu).

J Thorac Cardiovasc Surg 2005;130:899-900

$0022-5223 / \$ 30.00$

Copyright $\odot 2005$ by The American Association for Thoracic Surgery

doi:10.1016/j.jtcvs.2005.01.019
Three days later, she underwent an aortic valve replacement with a bioprosthetic valve. Her intraoperative and

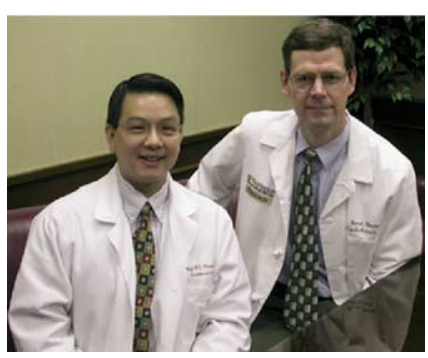

Choong and Meyers postoperative courses were uneventful and without evidence of recurrent PA hemorrhage. Before discharge, she was anticoagulated for her atrial fibrillation. At 2 years' follow-up, she had remained clinically well.

\section{Discussion}

Catheter-induced PA rupture is an infrequent but lethal complication occurring with an estimated frequency of $0.06 \%$ to $0.2 \%$. $^{1}$ Reported risk factors for catheter-induced PA rupture have included advanced age (age $>60$ years), catheter stiffness, prolonged balloon inflation, multiple manipulations of the catheter, peripheral placement of the catheter, pulmonary hypertension, and anticoagulation. ${ }^{1,2}$ Common modes of presentations have included hemoptysis with hypoxemia, exsanguination, delayed recurrent hemorrhage, and intraoperative pulmonary hemorrhage during or after cardiopulmonary bypass. ${ }^{3}$ False aneurysm of the PA is a rare presentation of PA rupture and should be considered as a possible diagnosis in a patient with a new lung mass after PA catheterization. ${ }^{4}$ Angiography is useful in the confirmation of the diagnosis and identification of the site of PA hemorrhage. ${ }^{5}$ Treatments have included control of the hemorrhage through conservative management, pulmonary resection, PA repair, and arterial embolization. Conservative management strategies have been associated with a high incidence of secondary and often fatal recurrent hemorrhage. ${ }^{1,3}$ Pulmonary resection is useful in controlling the bleeding but is associated with a high mortality and is reserved as a last resort. $^{3}$ Management by means of occlusion of the site of PA hemorrhage through embolization is the preferred initial treatment of choice and has the advantages of being quick, simple, and effective. ${ }^{5}$ Mortality from PA rupture, however, remains high, around $50 \%$, with uncontrolled hemorrhage leading to asphyxiation as the leading cause of death. ${ }^{1,3}$

In summary, we report of case of PA false aneurysm caused by catheter-induced PA rupture that presented as a new lung mass after PA catheterization. The diagnosis was confirmed by angiog- 